\title{
Performance Indicators and Benchmarking in Manufacturing Planning and Control Systems
}

\author{
A.K. Kochhar, A.J. Davies and M.P. Kennerley \\ UMIST \\ Manufacturing Division, Department of Mechanical Engineering, \\ Manchester, M60 1QD, United Kingdom \\ Telephone +44 161200 3801, Fax +44161 200 3803, \\ E-mail A.J.Davies@umist.ac.uk, M.P.Kennerley@umist.ac.uk,
}

\begin{abstract}
The recent, much publicised, interest in Benchmarking and Performance Measurement has not resulted in many of the anticipated benefits. Much of the benchmarking carried out in manufacturing organisations relates to top level issues. For benchmarking to be of real value, the best practices associated with lower levels of an organisation, which contribute to its overall performance, also need to be considered. It is particularly important to take account of manufacturing planning and control systems which interface with almost all of the activities carried out by a manufacturing organisation. This paper describes the findings of detailed fieldwork undertaken to investigate the use of benchmarking and performance indicators in manufacturing planning and control systems. It is concluded that a considerable amount of research work is needed to develop a detailed understanding of the relationships between performance measures, the contributing variables and the associated best practices.
\end{abstract}

\section{Keywords}

Manufacturing planning and control systems, performance measurement, benchmarking, best practice. 


\section{INTRODUCTION}

In recent years, a considerable amount of new thinking has emerged in the area of manufacturing. Traditional financial measures of performance are no longer regarded as adequate for the new style of highly competitive, world class manufacturing systems. Consumers are becoming ever more powerful and only companies that are sensitive to their changing requirements and are able to give them what they want will survive and prosper in the marketplace. As market requirements change, the strategies employed to maintain or achieve a higher share of the market must also change. These changes must be reflected in the measures used to evaluate the success of the strategies.

The actual manufacture and assembly of products represents the most significant and complex part of any manufacturing organisation. It is within the design and execution of manufacturing that the greatest impact on the competitive parameters of quality, cost, delivery and flexibility is made. The largest payback in any operation occurs at the point of manufacture ${ }^{(1)}$. In order to be flexible, decisions need to be made at the lowest possible level to allow rapid action. The quality of these decisions is directly related to the information available. Hence accurate information is required at the point of use, at the right time, and in a form that clearly indicates the required action. A good, well-planned performance measurement system should provide a framework that will give people lower down the organisation the performance data they need to make decisions. This can move decisionmaking down to the operational level which should allow improved performance in each of the parameters of quality, cost, delivery and flexibility.

Measurement must be followed by actions which lead to improved performance. Such actions may be based on existing well-known best practices. Alternatively, these actions may be based on the application of benchmarking techniques. Benchmarking involves looking at best practices, external to the company, to adapt them, for use in the company, in order to achieve superior performance. Anderson Consulting ${ }^{(2)}$ regard benchmarking as the most powerful tool for assessing industrial competitiveness and for triggering the change process in companies striving for world class performance. After a benchmarking study one can no longer hide behind excuses or put the clock back - one has to face the facts, however unpleasant, and act ${ }^{(2)}$. Benchmarking is a very realistic way to assess where a company is in relation to its competitors. It also provides realistic achievable targets and establishes how much a company needs to do to reach world class levels of functional and cross-functional performance ${ }^{(3)}$. Miller et $\mathrm{al}^{(4)}$ classify benchmarking into four types, namely strategic, product, functional and best practice, and recommend that all four types should be used so that every member of the organisation is involved.

The recent high level of interest in the two related areas of Performance Measurement and Benchmarking, has resulted in actual benchmarking being undertaken mainly at top levels of manufacturing organisations. In contrast, real sustainable improvement of manufacturing activities requires an assessment of performance at lower levels of an organisation and the use or adaptation of best practices. For example, manufacturing planning and control systems make a very significant impact on the achievement of the competitive priorities of quality, cost, delivery and flexibility, and all of the detailed activities undertaken in a manufacturing organisation. Very little performance measurement and benchmarking has been undertaken in 
this area. A large number of manufacturing planning and control performance indicators can be and should be used. Typical performance indicators include master production schedule adherence, purchase order issue timeliners, supplier due data compliance, shop floor schedule adherence, work in progress stockturns, and so on.

It is not the purpose of this paper to discuss the well rehearsed details of typical manufacturing planning and control systems. Many publications, for example texts by Vollman et $\mathrm{al}^{(5)}$ and Green ${ }^{(6)}$ provide comprehensive details of the functionality and operation of typical manufacturing planning and control systems.

As part of ongoing research in performance measurement and benchmarking ${ }^{(7)}$, detailed field studies were carried out to investigate the extent of performance measurement and benchmarking at the manufacturing planning and control system level, and the use of associated processes, performances measures and practices.

\section{FIELD STUDIES}

The field studies were designed to achieve the following related objectives:

- identify the measures of performance used to assess the efficiency and effectiveness of the manufacturing planning and control system;

- assess the priority associated with individual measures of performance;

- ascertain the actual values for specified measures of performance;

- assess the critical issues in the performance of manufacturing planning and control systems;

- assess the understanding of causal relationships;

- assess the cost and difficulties of collecting data relating to measures of performance;

- assess the effect of manipulating variables on performance indicators;

- assess actions which help to achieve higher levels of performance;

- confirm the practices and benchmarks which are considered to be 'best'.

An overall framework was created to structure the data collection and analysis process. The overall field study involved the following processes.

1. Preliminary interview with the senior management to obtain background information about the company. Questions at this introductory high level related to company products, strategy, organisational structure, major financial and production data, and the company environment.

2. Definition of the manufacturing planning and control systems used by the company, procedures for assessing performance and identification of the 'owners' of the particular modules and hence the interviewees for the main field study questions.

3. Identification of any organised benchmarking activities undertaken by the company.

4. Identification of critical success factors for the organisation. 
5. For each of the major modules of the manufacturing planning and control system used by the company, the following information was collected.

(a) The process of the module in terms of:

- objectives;

- inputs;

- outputs;

- boundary conditions;

- tools and techniques used;

- activities undertaken.

(b) Measures of performance (MOP's) used to assess the performance of the module.

- formal measures for assessing:

- effectiveness of the module;

- efficiency of the module.

- informal measures.

- detailed information relating to the data collection, analysis, reporting, ownership, costs, controllability, visibility, and actions for each measure of performance.

- targets, their setting and review process.

- best known benchmark for each measure of performance.

(c) Best practices used to improve the values of individual measures of performance.

(d) Awareness of other best practices and why they are not used.

(e) Overall benchmarking, as well as manufacturing planning and control system benchmarking, carried out by the organisation.

(f) Relationships between manufacturing planning and control system MOP's and the overall performance of the organisation.

(g) Planned developments in relation to measures of performance and best practices.

Four companies were visited and studied in very considerable depth. Although four companies constitute a small sample, their characteristics are such that they are representative of a significant proportion of manufacturing industry engaged in the batch manufacture of engineering products.

Each field study involved a considerable amount of preparation by the staff of the company involved as well as the interviewers. Actual data was collected during face to face interviews with a number of people who 'owned' and/or operated particular modules of the overall manufacturing planning and control system. The data was collected by two researchers over a period of one week in each company. This was followed by further visits to obtain clarifications and missing data. A very detailed report was prepared for each field study company and sent to the company management. Subsequently, a verbal presentation was done during which the main findings were presented, followed by an assessment of the findings. The presentations took the form of an interactive workshop which resulted in the development of action plans to be used within the company. The detailed reports of all field studies have been analysed to bring together the main findings as discussed in the next section. 


\section{MAIN FINDINGS}

The main findings of the field studies are as follows:

- There was little measurement of the effectiveness and efficiency of manufacturing planning and control (MPC) systems, particularly in relation to the strategic objectives. Performance measurement concentrated on the execution areas of the MPC system rather than the planning areas. There was no consistent approach to performance measurement at any of the sites and there was little formalised or structured understanding of cause and effect relationships.

- Very few formal structured benchmarking projects have been carried out in the area of MPC systems. Company visits were undertaken and provided a useful insight into improvement opportunities but a more formal benchmarking process is required to maximise the benefit of such activities. There was no formal benchmarking strategy at any of the sites leading to confusion as to what benchmarking involves. As a result there tended to be a preoccupation with metrics rather than the practices behind superior performance.

- Overall production/business planning was not explicitly carried out on any of the sites. It was largely a budgeting activity. There was integration with the master scheduling process and shop floor scheduling as the same personnel seemed to be involved in each process although feedback tended to be informal. There was a relatively little formal feedback to the production plan to revise financial and capacity plans.

- There was little formal performance measurement undertaken in the sales order processing module. There tended to be monitoring of progress against budgets for individual products/projects but there was no measurement across the company as a whole. Such measurement would indicate the areas in which performance should be improved. There tended to be good communication between the master scheduler, shop floor and sales in terms of agreeing due dates.

- There was no measurement of the accuracy of demand forecasting. The accuracy of demand forecasts is important for all types of companies in order to improve resource planning. The lack of consideration of forecast accuracy at the planning stages pushed uncertainty down to the execution areas where it was more difficult to cope with.

- The performance of the master production scheduling module was measured at the shop floor level. Schedule adherence was the main measure although this measured adherence to the plan rather than how accurate or achievable the plan was or how well it satisfied customer requirements.

- In all companies, rough cut resource planning was an informal and simple process. No consideration was given to parts availability within rough cut resource planning and there was no formal measurement of the availability of capacity or the accuracy of this process.

- In the companies visited, the MRP systems tended to deal with procurement rather than the issuing of shop orders. There was no regular measurement of the accuracy of the information in the system used for the planning of material requirements at any of the sites. 
- There was no measurement of BOM accuracy at any of the sites and there was little feedback from shop floor to identify performance problems.

- There were formal procedures and clear ownership for the engineering change control process in place at all sites. There was little formal performance measurement with preference being given to informal reviews. Where measures were used, or planned, there was a tendency to make them over complex in this area.

- Purchasing was the area with the most developed strategically based performance measures and where most significant effort had been made to implement practices to improve these measures. Some supplier development had been undertaken at all sites.

- Stock accuracy was a major issue in all companies and was measured at each of the sites. There was a need for more stock control in relation to semi-dormant and obsolete items and more regular reviews of current and active stock.

- No formal detailed capacity planning was undertaken at any of the sites.

- The shop loading and scheduling process tended to be clear and simple and was mainly concerned with the allocation of labour. Due date appeared to be the main priority rule.

- Shop floor monitoring and control was one of the areas in which most measurement of performance was undertaken. However, there was little prioritisation of measures and measurement was not always strategically based. Ownership of measures of performance was delegated well at two of the sites.

- Little finished goods inventory was held by any of the sites, hence finished goods inventory control was informal and simple. Simplicity and visibility were important for this process in each of the companies.

- The areas that had the most developed measures of performance and practices tended to be the areas that historically have been the focus of attention, mostly due to financial measurement and control. For example, purchasing because it tended to be the main area of expense within the organisation, and the shop floor as it dealt with output and work in progress. Also, these areas are the easiest to measure. Although the execution areas were the most measured areas, it was often the planning areas which caused poor performance and these areas were not measured. This problem is exacerbated by the fact that there was inadequate feedback from the execution areas back into the top level plans in order to create more realistic plans.

- The implementation of good practices within manufacturing planning and control systems appeared to be strongest in the area of purchasing, particularly in relation to supplier development. This was due to the vast amount of literature that has paid attention to this area in recent years.

- Ownership and definition of modules within the manufacturing planning and control systems was often unclear. This caused problems in the ownership of measures and practices.

- High product quality appeared to be implicit throughout the four organisations, with quality departments and a large number of measures supporting this. However, the other competitive priorities of delivery and flexibility were not as well communicated, or made the focus of attention at all levels of the organisation. 
- Many companies advocated due date compliance as one of their critical success factors, although there was a lack of communication and emphasis on this. In many cases, it was not measured until the end product was finished. There was a need in all companies for more focus to be placed on this measure at all levels of the manufacturing planning and control system.

- There was a lack of structured framework or strategy for measuring performance within organisations. As a result, there was little evidence of strategically based measures being in place. There was also little education on the need and use of performance measurement.

- On the whole, benchmarking was very limited and there were many misconceptions about what benchmarking involves. Many managers had a preoccupation with metrics, to the exclusion of practices.

- Cause and effect relationships between objectives, measures, variables and practices were not clear and thus were difficult to identify within the organisations studied.

\section{CONCLUSION}

Much performance measurement and benchmarking is carried out at business level. While this is of value, to be truly effective, benchmarking and the associated measurement of performance need to be aimed at other, contributory levels within a business. As a result, the measurement of, and targets for, strategic objectives can be developed throughout the organisation and focused on the areas that can satisfy them. This has particular importance within manufacturing planning and control systems as they are designed to co-ordinate the execution of manufacturing activities to support customer requirements and strategic objectives.

The findings of the fieldwork, outlined in this paper, clearly indicate lack of effective measurement of performance and benchmarking in relation to manufacturing planning and control activities. These findings support the belief that, in many organisations, computerbased manufacturing planning and control systems are simply no more than transaction processing systems which contribute relatively little to effective decision-making and continuous improvement of manufacturing systems. While there is a reasonable knowledge of best practices, especially in relation to execution modules, there is relatively little understanding of cause and effect relationships. A considerable amount of further research is necessary to develop this knowledge and improve the decision-making at lower levels, in manufacturing organisations, which contribute to the overall performance of an integrated and sustainable industrial system.

\section{ACKNOWLEDGEMENTS}

The authors are grateful to the Control, Design and Production Group of the British Engineering and Physical Sciences Research Council (EPSRC) for the award of a research 
grant to undertake the research described in this paper. They are also grateful to the companies in which field studies were undertaken.

\section{REFERENCES}

(1) Martin, P.G. (1993) Dynamic performance measurement: The path to World Class Mamufacturing, Van Nostrant Reinbold.

(2) Anderson Consulting (1993) The Lean Enterprise Benchmarking Project, Arthur Anderson \& Co.

(3) Walleck, A.S., O'Halloran, J.D. and Leader, C.A. (1991) Benchmarking World Class Performance, McKinsey Quarterly, Number 1, p3-24.

(4) Miller, J.G., Meyer, A. and Nakare, J. (1992) Benchmarking Global Manufacturing, Irwin.

(5) Vollmann, T.E., Berry, W.L. and Whybark, C. (1992) Manufacturing Planning and Control Systems, Irwin, Third Edition.

(6) Green, J. H. (1987) Production and Inventory Control Handbook, APICS, McGrawHill, Second Edition.

(7) Kennerley, M.P., Davies, A.J. and Kochhar, A.K. (1996) Manufacturing Strategy, Performance and Best Practices - the contribution of the Manufacturing Planning and Control Systems, Proceedings of 3rd International Conference of European Operators Management Association, London 2-4 June, 363-368.

\section{BIOGRAPHY}

Professor A K Kochhar is the Lucas Professor of Manufacturing Systems Engineering and Head of the Manufacturing Division of the Department of Mechanical Engineering at UMIST. His main research interests are Computer-Aided Production Management Systems; and the Design, Planning and Control of Manufacturing Systems.

Amanda Davies is a research assistant in the Manufacturing Division of the Department of Mechanical Engineering at the University of Manchester Institute of Science and Technology (UMIST). Her main research interest is Benchmarking and Best Practices within Manufacturing Planning and Control Systems.

Mike Kennerley is a research assistant in the Manufacturing Division of the Department of Mechanical Engineering at the University of Manchester Institute of Science and Technology (UMIST). His main research interest is Performance Measurement of Manufacturing Planning and Control Systems. 